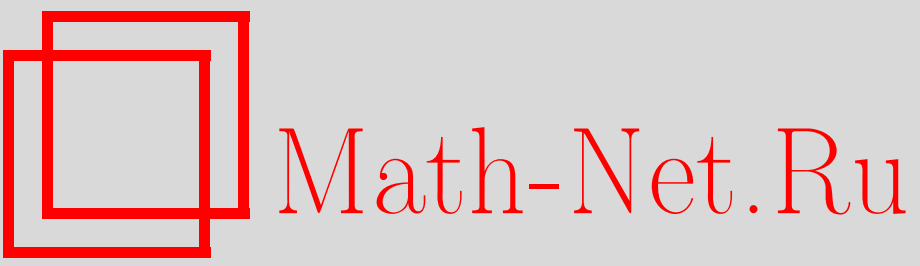

Г. Гутиеррес, О правиле фаз Гиббса, ТМФ, 1996, том 108, номер 3, 465-468

DOI: https://doi.org/10.4213/tmf1203

Использование Общероссийского математического портала Math-Net.Ru подразумевает, что вы прочитали и согласны с пользовательским соглашением

http: //www.mathnet.ru/rus/agreement

Параметры загрузки:

IP : 54.224 .60 .19

26 апреля 2023 г., 16:40:06 
ТЕОРЕТИЧЕСКАЯ

И МАТЕМАТИЧЕСКАЯ

ФИЗИКА

Том 108, № 3

сентябрь, 1996

\section{G. Gutiérrez}

\section{GIBBS' PHASE RULE REVISITED}

Gibbs' phase rule and related properties of phase diagrams are obtained using simple combinatorial methods of associating a graph to each thermodynamic system. We think this approach allows a deeper understanding of the geometrical roots of this rule.

\section{INTRODUCTION}

Gibbs' phase rule [1] is a result which was obtained from very general properties of the fundamental equation and equilibrium conditions of a thermodynamic system. Its deduction in modern thermodynamic books (see for example [2]) could be phrased as follows: Given a system with $r$ components and $M$ coexistent phases, there are $r+2$ intensive parameters, $T, P, \mu_{1}, \ldots, \mu_{r}$. Each of these parameters are constant from phase to phase. In each of the $M$ phases, there is a Gibbs-Duhem relation among these variables. These $M$ equations reduce the number of independent parameters to $(r+2)-M$. The degree of freedom $f$ is then

$$
f=r-M+2 .
$$

The above equation is proved solving a system of equations and using the relation between the number of equations and the variables, as is usually done in Linear Algebra ${ }^{1}$. However, because we are dealing here with thermodynamic surfaces (and not only planes), the above argument cannot be considered a rigorous proof.

In fact, there are several papers that emphasize this point, although their approach is different from ours. See [3] and the references therein.

The objective of this paper is to discuss Gibbs' phase rule from a different viewpoint, based on the fact that Gibbs' phase rule is not a consequence of analytic properties of the fundamental equation, but of the combinatorial properties of phases and their coexistence.

\section{GIBBS' PHASE RULE FOR SUBSTANCES WITH $r$ COMPONENTS}

In classical thermodynamics, the state of a substance with $r$ components is characterized by the fundamental equation $U=U\left(S, V, N_{1}, \ldots, N_{r}\right)$. The Legendre transform with respect to certain variables leads us to different thermodynamic potentials. The stability conditions constrain these potentials so that they are convex functions of their extensive variables and concave functions of their intensive variables.

\footnotetext{
1) Using this method, it is proved that two planes intersect in a line, three planes in a point, and so
} on 
In particular, if we apply the complete Legendre transform to $U=U\left(S, V, N_{1}, \ldots, N_{r}\right)$, we obtain the thermodynamic potential $U=U\left[T, P, \mu_{1}, \ldots, \mu_{r}\right]$. Using the Gibbs-Duhem relation, this is equivalent to an $r+1$-variable potential $\mu_{r}=\mu_{r}\left[T, P, \mu_{1}, \ldots, \mu_{r-1}\right]$, which can be represented by a hypersurface which exists in $r+2$ dimensions ${ }^{2}$.

The thermodynamic equilibrium conditions between systems I and II are given by the thermal equilibrium $T^{\mathrm{I}}=T^{\mathrm{II}}$, the mechanical equilibrium $P^{\mathrm{I}}=P^{\mathrm{II}}$ and the equilibrium with respect to material flow $\mu^{\mathrm{I}}=\mu^{\mathrm{II}}$. In the case of a substance with different phases, the system can be considered to be composed of simple thermodynamic subsystems divided by nonrestrictive walls. So, each different phase will have an associated thermodynamic potential, and the coexistence of these phases can be treated in the same way as the balance among thermodynamic systems.

For each of these different phases $i$ of the substance, there is a different equation $\mu_{r}^{i}$. These different phases coexist if and only if they have the same values for each of their $r+1$ intensive variables $T, P$ and $\mu_{1}, \ldots, \mu_{r-1}$.

In this form, the condition of coexistence of $M$ phases for a substance of $r$ components can be reduced to the following two axioms:

Axiom 1. If the phases $f_{1}, \ldots, f_{M}$ coexist, then each pair $f_{i}, f_{j}$ coexists for a hypersurface of dimension less than the dimension of the hypersurface which represents the phase.

Axiom 2. If two phases $f_{i}, f_{j}$ coincide in an entire region of the same dimension, then $f_{i}=f_{j}$.

\section{THE PHASE GRAPH OF A SYSTEM}

Now, we are going to associate a graph to each of the $r$ components (to review graph definitions, see [4]), called the phase graph $G(r)$, in the following way:

To each phase $f_{i}$, we associated a vertex $v_{i}$.

To each border between $f_{i}$ and $f_{j}$ (hypersurface where $f_{i}, f_{j}$ coexist), if it exists, we associate the edge $\left(v_{i}, v_{j}\right)$ which connects vertices $v_{i}$ and $v_{j}$.

Phase graphs have the following simple properties:

ProperTy 1. Each graph $G(r)$ is composed of complete subgraphs $K_{j}, j \in\{1, \ldots, n\}$, whose maximum number of vertices $j$ is $n=r+2$ and corresponds to the number of vertices of the simplex [5] in $(r+1)$ dimensions ${ }^{3}$.

Property 2. For each of these complete subgraphs $K_{j}$ of $G(r)$, let us define

$$
\operatorname{deg} f r\left(K_{j}\right)=(r+1)-d g\left(K_{j}\right)
$$

where $d g\left(K_{j}\right)=j-1$ is the common degree of the vertices of $K_{j}$. Then deg $f r$ represents the dimension of the hypersurface where $f_{i 1} \cdots f_{i j}$ coexist (this follows immediately from Axiom 1, Axiom 2 and Property 1).

\footnotetext{
${ }^{2)}$ It is not difficult to realize that this hypersurface is concave, even though this condition is not needed in our reasoning.

${ }^{3)}$ In a hypersurface of dimension $l$, the simplex has $l+1$ vertices.
} 

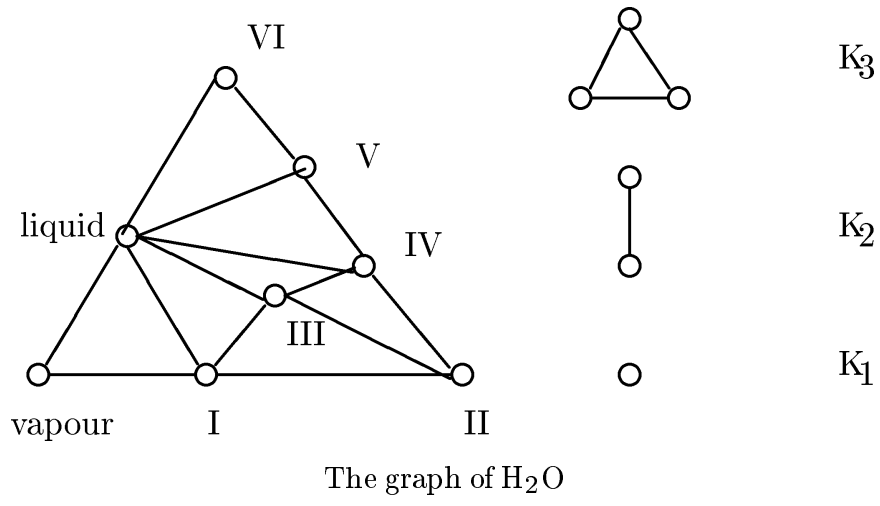

$\mathrm{K}_{3}$

A number of physical consequences can be deduced from $G(r)$. We will give some of them, and illustrate them with two examples.

1. From Property 1 , the maximum number of phases that can coexist in a system with $r$ components is $r+2$. In this case deg $f r\left(K_{r+2}\right)=0$, that is, the $r+2$ phases coexist at a single point which is called the " $(r+2)$-point".

2. In general, when $M$ phases coexist (so we are in the case $K_{M}$ ), using the fact that $d g\left(K_{M}\right)=M-1$, we have

$$
\operatorname{deg} f r\left(K_{M}\right)=r-M+2,
$$

which is nothing less than Gibbs' phase rule for a pure substance where deg $\operatorname{fr}\left(K_{M}\right)$ represent the thermodynamic degree of freedom.

3. Each complete subgraph $K_{n}$ of $G(r)$ corresponds to different physical conditions of the system. So, it can be the case that the system has many $(r+2)$-points, $(r+$ 1)-points, etc.

EXAMPLES:

a) In particular, let us consider the case of water. It is a substance with one component $(r=1)$. The associated graph $G(1)$ is shown in Figure. It is composed of the complete subgraphs $K_{1}, K_{2}, K_{3}$, which correspond to the coexistence of one, two or three phases, respectively. There are 7 triple points (the seven $K_{3}$ 's in the Figure), 14 cases of coexistence of two phases (the fourthteen $K_{2}$ 's) and 8 phases (the eight $K_{1}$ 's or vertices).

b) For a substance with 2 components, let us suppose that there are 4 certain phases in equilibrium among themselves. Then we can say that there can be 4 different triples of coexisting phases with 1 degree of freedom, 6 pairs of coexisting phases with 2 degrees of freedom, and 4 different phases with 3 degrees of freedom. In general, this corresponds to considering a simplex of $M$ vertices and counting the number of hyperplanes of lower dimensions that it has. It is known (see, e.g., [5]) that this number is given by

$$
f_{k}\left(T^{d}\right)=\left(\begin{array}{l}
d+1 \\
k+1
\end{array}\right)
$$

where $d$ is the dimension of the hyperplane and $k$ is the number of faces, with $k<d$. In the previous example, the dimension of the hyperplane is $d=3$, so we obtain the different values from $f_{k}\left(T^{3}\right)$. 
Acknowledgments. The author acknowledges the useful conversations with R. Benguria, C. Friedli, and D. Sankovich at the first stage of this work, and wishes to thank C. Gutiérrez for a number of helpful suggestions and valuable discussions. This work was partially supported by the Fondo Nacional de Investigaciones Científicas y Tecnológicas (FONDECYT, Chile) under Grant 2940022.

\section{References}

[1] The Scientific Papers of J. Williard Gibbs, Vol. 1, "Thermodynamics". New York: Dover Publications, 1961

[2] C. J. Adkins. Equilibrium thermodynamics, Third Edition: Cambridge University Press, 1983; I. P. Bazarov. Thermodynamics: Pergamon Press (The Mac Millan Company), 1964. P. 155;

H. Callen. Thermodynamics and an introduction to Thermostatistics, Second Ed: John Wiley \& Sons, 1985. P. 247.

[3] W. Noll // Arch. Rational Mech. Anal. 1970. V. 38. P. 1-12; M. Feinberg // Arch. Rational Mech. Anal. 1979. V. 70. P. 219-234; C. -S. Man // Arch. Rational Mech. Anal. 1985. V. 91. P. 1-53.

[4] F. Harary. Graph Theory. Reading, Mass.: Addison-Wesley, 1969.

[5] B. Grünbaum. Convex Polytopes. New York: Wiley (Interscience), 1967.

Facultad de Física, P. Universidad Católica de Chile,

Casilla 306, Santiago 22, Chile

Поступила в редакцию

e-mail: ggutierr@lascar.puc.cl

5.IX.1995 г.

\section{Г. Гутиеррес \\ О ПРАВИЛЕ ФАЗ ГИББСА}

С помощью комбинаторных методов, ассоциирующих с каждой термодинамической системой граф, получено гиббсовское правило фаз и описаны соответствующие свойства фазовых диаграмм. Мы полагаем, что данный подход позволяет глубже понять геометрические корни этого правила. 